BLESSED, G. \& WILSON, I. D. (1982) The contemporary natural history of mental disorder in old age. British Journal of Psychiatry. $141,59-67$.

CrRustre, A. B. (1982) Changing patterns in mental illness in the elderly. British Journal of Psychiatry, 140, $154-159$.

GraHAME, P. S. (1982) Late paraphrenia. British Journal of Hospital Medicine, 27, 522-528.

GrAHAME, P. S. (1984) Schizophrenia in old age (late paraphrenia). British Journal of Psychiatry, 145, 493-495.

KAY, D. W. K. \& ROTH, M. (1961) Environmental and hereditary factors in the schizophrenias of old age (late paraphrenia) and their bearing on the general problem of causation in schizophrenia. Joumal of Mental Science, 107, 649-686.

Post, F. (1966) Persistent Persecutory States of the Elderly. Oxford: Pergamon Press.

Roth, M. (1955) The natural history of mental disorder in old age. Journal of Mental Science, 101, 281-301.

\section{Comparative Trial of a New Antidepressant}

SIR: There are 16 tricyclic and related antidepressants currently on the market. It seems likely that most psychiatrists use only a small number of them routinely. Before any more new antidepressants are added to this list, how insistent should we be in requiring that standardised methodologies be employed when testing their efficacy?

Levine et al (Journal, May 1987, 150, 653-655) showed that fluoxetine was as effective an antidepressant as imipramine. However, their study did not include a placebo control to establish the relative efficacy of both of these drugs. The reason for this not uncommon omission is that imipramine is considered to be of proven efficacy and, therefore, a reliable benchmark against which new antidepressants can be measured. How justified is this assumption?

In two extensive reviews of the literature, tricyclic antidepressants were not found to be superior to placebo in 35\% (Morris \& Beck, 1974) and $41 \%$ (Thomson, 1982) of studies. Swallowing an inert placebo leads to a significant improvement in between 30\% (Morris \& Beck, 1974) and 50\% (Medical Research Council, 1965) of those suffering from depression. Mild side-effects (which fluoxetine possesses) are associated with greater drug success, while zero or severe side-effects are associated with less success (Brune et al, 1962). The advantage of tricyclic antidepressants over placebo is significantly less when an active (atropine) placebo is used instead of an inert substance (Thomson, 1982). Thirty per cent of depressed patients do not respond to tricyclic antidepressants (Medical Research Council, 1965): in the Levine et al study this figure was approximately $50 \%$.

Thus the universal and invariable efficacy of tricyclic antidepressants has yet to be demonstrated.
Therefore, imipramine and other 'standard' antidepressants should not be used as the sole agent in comparative studies. Levine et al did not use a placebo control, so we cannot be sure whether the improvement in depressive symptoms was due to a specific psychotropic, or an active placebo, effect.

\section{St Thomas' Hospital}

JoHN DUNN

\section{London SEI}

\section{References}

Brune, G., Morpugo, C. \& Bieluus (1962) Relevance of drug induced extrapyramidal reactions to behavioural changes during neuroleptic treatment. Comprehensive Psychiatry, 3, 227-234.

Medical Research Counch (1965) Clinical trial of the treatment of depressive illness. British Medical Journal, i, 881-886.

MorRIs, J. \& BECK, A. (1974) The efficacy of antidepressant drugs. Archives of General Psychiatry, 30, 667-674.

ThOMSON, R. (1982) Side-effects and placebo amplification. British Joumal of Psychiatry, 140, 64-68.

\section{Comparative Hospital Survey of Psychotropic Drug Prescribing}

SIR: Muijen \& Silverstone (Journal, April 1987, 150 , 501-504) showed that the hospital (hospital A) with the lowest prevalence of polypharmacy was the only one with an associated psychopharmacology unit. We have compared the authors' results with our acute in-patient population. Our data is obtained from a unit in our hospital, the population of which can be compared to that of the authors' hospital $C$. Ours is a teaching hospital, but has no association with any psychopharmacology unit.

Seventy-eight patients admitted in the past year were included in the study. All psychotropic drugs given on the seventh day of admission were recorded from case records; we presumed that a final diagnosis was reached and medication was started by one week after admission. The rest of our methodology is similar to that of the authors' study.

The results showed that more than one psychotropic drug was given to 49 patients $(63 \%)$. This figure is close to the authors' figure for hospital A. More than two drugs were given to 23 patients $(29 \%)$ and more than three drugs were given to 8 patients $(10 \%)$. One patient received no drugs, one drug was given to 23 patients ( $29 \%$ ), two drugs were given to 28 patients $(36 \%)$ and three drugs were given to 18 patients $(23 \%)$. Benzodiazepines were given to 22 patients $(28 \%)$. More than one antipsychotic drug was given to 21 patients $(27 \%)$, whereas antiparkinsonian drugs were given to 17 patients $(22 \%)$. The last two figures are lower than the authors' 
hospital A figures. We conclude that drug prescription is more influenced by general training than by any association with a psychopharmacology unit.

H. V. KUMAR S. FINLEY

\author{
St Vincent's Hospital \\ Richmond Road \\ Fairview \\ Dublin 3
}

\section{Compulsory Detention of Males of Different Ethnic Groups}

SIR: We wish to comment on the article by McGovern \& Cope (Journal, April 1987, 150, 505-512).

Since 1976 the Mersey Region has had a secure unit, initially in the form of an interim facility and since 1983 as a regional secure unit. The unit accepts referrals from special hospitals, prisons, remand centres and other psychiatric hospitals. Our clinical impression was that admission rates for patients of West African and West Indian descent were in proportion to their numerical size in our catchment population. In the light of the above study we examined our data relating to admissions for a defined part of our catchment area, in which patients in the category defined above make up $6 \%$ of the population.

Since 1976 there have been 93 admissions to our unit from the defined area ( 78 male and 15 female): 14 patients were of West African or West Indian descent. Of the 93 admissions, 63 were offenders and 30 non-offenders. Patients of West African or West Indian descent were over-represented among offenders $(12 / 63)$ but not among non-offenders $(2 / 30)$.

Our figures support the findings of McGovern \& Cope. We are unable to account for these differences, but can say that our clinical experience does not support the suggestion that patients of West African or West Indian descent are more disturbed, violent, or difficult to follow-up in the community. We are currently planning a survey in a larger sample including special hospital patients.

G. SHETTY

Scott Clinic

R. HIGGO

Rainhill Hospital

Prescot

Merseyside L35 4PQ

\section{The Psychological Well-Being of Supporters of the Demented Elderly}

SIR: Two things puzzle me about the paper by Eagles et al (Journal, March 1987, 150, 293-298). Firstly, it seems little short of miraculous that the 1980-1982 MSQ had $100 \%$ sensitivity, specificity, and predictive values with the 1983-1984 psychiatric assessment of the presence of dementia in the "dependants" of the first 80 supporters agreeing to the interview. It is not clear whether this represents a startling improvement in psychiatric epidemiology, or whether there is some more prosaic reason.

Secondly, why were the 'non-demented' elderly people in this survey being "supported" at all? It is likely from the way they were apparently recruited that they were having problems, but since the vast majority of 'non-demented' elderly people look after themselves perfectly well, there must have been something else going on here. This, rather than the explanations offered in the discussion, may explain why GHQ scores did not differentiate between the groups.

It is a pity that such elementary points of clarifcation could not be dealt with before the paper was published.

A. J. D. MACDONALD

Community Team for Mental Health in the Elderly

Hither Green Hospital

Hither Green Lane

London SE13 6RU

SIR: Macdonald's puzzlement stems from his having misunderstood the methodology of our study. The MSQ carried out in 1980-82 allowed identification of a group of elderly patients who were living at home and were possibly demented, since their MSQ score was 8 or less at that time. These 205 subjects were matched for age and sex with 205 subjects scoring 9 or 10 on the MSQ. These subjects were then reinterviewed in 1983-84 with the aim of, among other things, assessing the follow-up validity of the MSQ. For the purposes of the present study, the 1980-82 MSQ was ignored and the ratings of the patients are those made during the psychiatrist's visit in 1983-84.

With regard to Macdonald's second point, the 'non-demented' people in this survey were not necessarily being "supported". We make it fairly clear that the criterion for their inclusion was that they were co-habiting with someone who was willing to complete our questionnaires, and that this co-habitee would bear the burden of support, if such support were necessary. I cannot understand Macdonald's contention about these patients that "from the way they were apparently recruited they were having problems". They were recruited solely on the basis that they were 'non-demented' elderly patients whose co-habiting relative was willing to 